\title{
Experimental and Runge-Kutta Method Simulation to Investigate Corrosion Kinetics of Mild Steel in Sulfuric Acid Solutions
}

\author{
Ismaeel M. Alwaan (D) \\ Department of Materials Engineering, College of Engineering, University of Kufa, Najaf, Iraq \\ Correspondence should be addressed to Ismaeel M. Alwaan; ism10alw@yahoo.com
}

Received 19 January 2018; Revised 14 May 2018; Accepted 12 June 2018; Published 8 July 2018

Academic Editor: Ramana M. Pidaparti

Copyright (C) 2018 Ismaeel M. Alwaan. This is an open access article distributed under the Creative Commons Attribution License, which permits unrestricted use, distribution, and reproduction in any medium, provided the original work is properly cited.

\begin{abstract}
The mild steel is extensively used in different industrial applications and the biggest problem in the application of mild steel is corrosion. In this work, the reaction kinetics of mild steel with sulfuric acid at different concentrations and at different temperatures were studied in combination with the experimental data and theoretical approach using the Runge-Kutta method. The results revealed that the rate of reaction constant for temperatures in the range of $30-50^{\circ} \mathrm{C}$ was changed from 2618 to $2793 \mathrm{~L}^{3} / \mathrm{mol}^{3} . \mathrm{h}$, respectively. The order of reaction of mild steel was $4^{\text {th }}$ order in all temperature ranges. The enthalpy, entropy, and Gibbs free energy of mild steel reaction at a temperature of $298 \mathrm{~K}$ were estimated. The activation energy (E/R) of the reaction was $4.829 \mathrm{~K}$. It was concluded that the sulfuric acid reaction with mild steel occurred easily and the inhibitors should be used in these systems.
\end{abstract}

\section{Introduction}

Mild steel alloy has been extensively utilized in manufacture as a substance for reaction containers, pipes, etc. [1]. Poor corrosion resistance of mild steel in corrosive electrolytes has largely prevented its implementation. Acid solutions are commonly used in different processes such as acid picking, cleaning, and descaling, which may cause the corrosion of metals [2, 3]. The alloy of mild steel destroyed by corrosive materials has led to significant economic losses and has created huge problems in industrial instrument security [4].

The investigation of mild steel corrosion and iron is a major theoretical issue and has attracted significant attention. Many scientists are conducting research on mild steel corrosion. The corrosion inhibitors of two imidazoline derivatives have been investigated for mild steel and the chloridesubstituted was found better as compared with the fluoridesubstituted [5]. The effect of 4,6-diamino-2-pyrimidinethiol (4D2P) inhibitor on mild steel oxidation in hydrochloride acid media was studied [6]. The rind, seed, and peel extract of watermelon were studied as corrosion inhibitor for mild steel in hydrochloride acid media [7].
Computational methods were extensively used for the purpose of designing new inhibitors with excellent inhibition characteristics. The simulations investigation was adopted to investigate corrosion-resisting aluminum and stainless steel pipes using 3D finite element model [8]. The sodium phosphate, sodium nitrite, and benzotriazole inhibitors were used to simulate steel metal in concrete pore solutions [9]. Thixoforging and simulation of complex parts of aluminum alloy $\mathrm{AlSi}_{7} \mathrm{Mg}$ were investigated [10]. A mathematical model was carried out for the sulfuric acid and ferric ion diffusion and the copper sulfide mineral leaching process [11]. Carbon fiber, carbon/carbon, and some modified carbon/carbon blends were exposed to a simulated atomic oxygen ambience to study their attitude in low earth orbit [12]. The reactions between silicon and nitrogen were studied using the shrinking core model [13]. Monte Carlo simulation technique was adopted to study the adsorption behavior of furan derivatives on mild steel face in hydrochloric acid [14]. Corrosion inhibition mechanism of two-mercaptoquinoline Schiff based on mild steel surface is investigated by quantum chemical calculation and molecular dynamics simulation [15]. 
TABLE 1: The chemical structure of mild steel specimen (weight percentage).

\begin{tabular}{lccccccccc}
\hline Elements & $\mathbf{C}$ & $\mathbf{S i}$ & $\mathbf{M n}$ & $\mathbf{P}$ & $\mathbf{S}$ & $\mathbf{C r}$ & $\mathbf{M o}$ & $\mathbf{C u}$ & $\mathbf{F e}$ \\
\hline Weight percentage (wt \%) & 0.19 & 0.26 & 0.64 & 0.06 & 0.05 & 0.08 & 0.02 & 0.27 & Bal. \\
\hline
\end{tabular}

Runge-Kutta method was extensively used for solving the different model of corrosion. Runge-Kutta, Euler-Maruyama, and Milstein methods were utilized to investigate the relationship between the time and pit corrosion depth in nuclear power plant piping systems [16]. The model is suggested to predict the precipitation allocation of corrosion output by using five-order Runge-Kutta format [17]. The Runge-Kutta method was used to solve the two-phase homogeneous model numerically and the major attitude of activated corrosion outputs [18]. A new partial differential model for monitoring and detecting copper corrosion products by sulfur dioxide $\left(\mathrm{SO}_{2}\right)$ pollution is proposed using Runge-Kutta method [19].

The present paper explores corrosion kinetics of mild steel in sulfuric acid solutions using weight loss techniques. The effect of temperature $\left(30-50^{\circ} \mathrm{C}\right)$ on corrosion is thoroughly assessed and discussed. Thermodynamic parameters were also calculated and discussed. The Runge-Kutta method was furthermore applied in an endeavor to obtain insights into the mechanism of corrosion of mild steel face at the molecular level.

\section{Experimental}

Mild steel sheet was mechanically press scissor into pieces of measuring $3 \times 2 \times 0.1 \mathrm{~cm}$. These pieces were utilized without polishing. However, surface curing of the pieces included cleaning, degreasing in absolute ethanol, and drying in acetone. Solutions of (0.1-0.5 M) $\mathrm{H}_{2} \mathrm{SO}_{4}$ were provided by dilution of $97 \%$ sulfuric acid (weight percentage) utilizing bidistilled water. The chemical structure of this alloy specimen is illustrated in Table 1.

Weight loss tests were conducted using beakers $(100 \mathrm{ml})$ of test solutions maintained at " $30^{\circ} \mathrm{C}$ " for different concentrations $(0.1,0.2,0.3,0.4$, and $0.5 \mathrm{M})$ under total immersion conditions. All tests were made in aerated solutions. Weight loss of the specimens was determined by keeping them in test solutions for a time period range of 1-5 days. After completing a duration of treatment time specimens were scrubbed with a bristle brush under running water in order to remove the corrosion product. Specimens were then dried and reweighed. The weight loss was taken as the difference between the weight at a given time and the initial weight and is determined by using LP 120 digital balance with sensitivity of $\pm 1 \mathrm{mg}$. The tests were performed in triplicate to guarantee the reliability of the results and the mean value of the weight loss is reported. Weight loss allowed calculation of the mean corrosion rate in $\mathrm{mg} / \mathrm{cm}^{2} \mathrm{~h}$.

\section{Theoretical}

3.1. The Runge-Kutta Method [20, 21]. The analytical details of the Runge-Kutta method can be outlined with reference to (1) below and an initial condition $\left(y=y_{o}\right.$ at $\left.x=x_{o}\right)$. It is desired to find the value of $(y)$ when $\left(x=x_{0}+h\right)$ where $(h)$ is some given constant:

$$
\frac{d y}{d x}=f(x, y)
$$

According to the Runge-Kutta method, it can be shown analytically that the ordinate at $\mathrm{x}=\mathrm{x}_{\mathrm{o}}+\mathrm{h}$ to the curve through $\left(\mathrm{x}_{\mathrm{o}}, \mathrm{y}_{\mathrm{o}}\right)$ is given by

$$
y=y_{o}+\frac{1}{6}(K 1+4 K 2+K 3)
$$

where $\mathrm{K}_{1}, \mathrm{~K}_{2}$, and $\mathrm{K}_{3}$ are given by the equations

$$
\begin{aligned}
& K 1=h \cdot f\left(x_{o}, y_{o}\right) \\
& K 2=h \cdot f\left(x_{o}+\frac{1}{2} h, y_{o}+\frac{1}{2} K 1\right) \\
& K 3=h \cdot f\left(x_{o}+h, y_{o}+2 K 2-K 1\right)
\end{aligned}
$$

Formula (2) is known as the third-order Runge-Kutta formula because the term corresponding to the third derivative term in the Taylor series for $y$ expanded about $\left(\mathrm{x}_{0}, \mathrm{y}_{\mathrm{o}}\right)$ is correct $[20,21]$.

A mathematical model for first-order ordinary differential equation can be found to be used in Rung-Kutta method. The mathematical model represents the relationship between the temperature and the rate of reaction as explained below:

The transition state equation $[22,23]$ is

$$
r=\frac{R T}{N h} * \operatorname{EXP}\left(\frac{\Delta S_{a}^{o}}{R}\right) * \operatorname{EXP}\left(\frac{-\Delta H_{a}^{o}}{R T}\right)
$$

where $r$ is the rate of reaction, $\Delta \mathrm{H}^{\mathrm{o}}{ }_{\mathrm{a}}$ is the enthalpy of activation at standard condition, $\Delta S^{\circ}$ a is the entropy of activation at standard condition, $\mathrm{h}$ is Planck's constant, and $\mathrm{N}$ is the Avogadro number.

Equation (6) is rearranged to obtain

$$
\frac{r}{T}=M * \operatorname{EXP}\left(\frac{-\Delta H_{a}^{o}}{R T}\right)
$$

where $\mathrm{M}=\mathrm{R} / \mathrm{Nh} * \operatorname{EXP}\left(\Delta \mathrm{S}^{\mathrm{o}}{ }_{\mathrm{a}} / \mathrm{R}\right)$

Take the $(\ln )$ function for both sides of (7) to get

$$
\begin{aligned}
\ln \left(\frac{r}{T}\right) & =\frac{-\Delta H_{a}^{o}}{R * T}+\ln (M) \\
\ln (r) & =\ln (T)-\frac{\Delta H_{a}^{o}}{R * T}+\ln (M)
\end{aligned}
$$

Derivate (9) to find

$$
\frac{1}{r} \frac{d r}{d T}=\frac{1}{T}+\frac{\Delta H_{a}^{o}}{R \cdot T^{2}}
$$


TABLE 2: Rate of reaction $\left(\mathrm{mg} / \mathrm{cm}^{2} . \mathrm{h}\right)$ of mild steel in sulfuric acid at $0.1 \mathrm{M}$ concentration and at different temperature $\left(30-50^{\circ} \mathrm{C}\right)$.

\begin{tabular}{lccc}
\hline Temperature $\left({ }^{\circ} \mathrm{C}\right)$ & $1 / \mathrm{T}\left(\mathrm{K}^{-1}\right)$ & $\begin{array}{l}\text { Rate }(\mathrm{r})\left(\mathrm{mg} / \mathrm{cm}^{2} \cdot \mathrm{h}\right) \\
\mathrm{AT} \mathrm{C}=0.1 \mathrm{M} \mathrm{H}_{2} \mathrm{SO}_{4}\end{array}$ & $\mathrm{r} / \mathrm{T}\left(\mathrm{mg} / \mathrm{cm}^{2} . \mathrm{h} . \mathrm{K}\right)$ \\
\hline 30 & 0.003299 & 0.175 & 0.000577 \\
35 & 0.003245 & 0.20275 & 0.000658 \\
40 & 0.003193 & 0.2305 & 0.000736 \\
45 & 0.003143 & 0.25825 & 0.000812 \\
50 & 0.003095 & 0.286 & 0.000885 \\
\hline
\end{tabular}

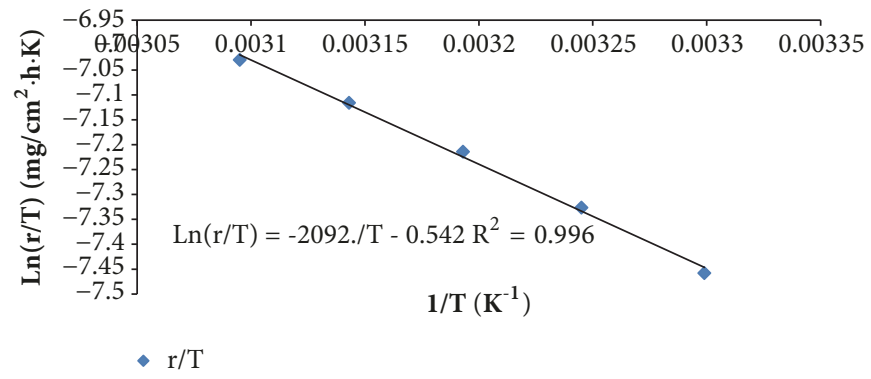

Figure 1: $\log (\mathrm{r} / \mathrm{T})$ versus $(1 / \mathrm{T})$ of mild steel in sulfuric acid at $(0.1 \mathrm{M})$ concentration and at different temperature $\left(30-50^{\circ} \mathrm{C}\right)$.

Multiply (10) by (r) and the result is

$$
\frac{d r}{d T}=\frac{r}{T}+\frac{r \cdot \Delta H_{a}^{o}}{R \cdot T^{2}}
$$

Equation (11) is the first-order ordinary differential equation which represents the relationship between the temperature $(\mathrm{T})$ and the rate of reaction $(\mathrm{r})$. This equation can be used in Rung-Kutta method to calculate the rate of reaction at different temperature $\left(30-50^{\circ} \mathrm{C}\right)$ for different concentration.

\section{Results and Discussion}

The corrosion of mild steel was studied in combination between the theoretical and experimental data to analyse the kinetics of reaction with sulfuric acid $\left(\mathrm{H}_{2} \mathrm{SO}_{4}\right)$ at various concentrations $(0.1-0.5 \mathrm{M})$. The theoretical data were obtained by numerical methods, especially by the Runge- Kutta method $[20,21]$. The corrosion rate of mild steel experimentally was determined using the relation:

$$
R=\frac{\Delta w}{A \cdot t}
$$

where $\Delta w$ is the mass loss, $\mathrm{A}$ is the area, and $\mathrm{t}$ is the immersion of period time.

The enthalpy $\Delta \mathrm{H}^{\mathrm{o}}$ a can be found using (11). The enthalpy $\Delta \mathrm{H}^{\mathrm{o}}$ a was found by plotting $\ln (\mathrm{r} / \mathrm{T})$ versus $1 / \mathrm{T}$ for the experimental data shown in Table 2 according to (8) to get a straight line. The slope of straight line represents $\Delta \mathrm{H}^{\mathrm{o}}{ }_{\mathrm{a}} / \mathrm{R}$ and the intercept is $\ln (\mathrm{M})$, where $\mathrm{M}$ is equal to $(\mathrm{R} / \mathrm{Nh} *$ $\operatorname{EXP}\left(\Delta S^{o}{ }_{a} / R\right)$ as shown in Table 2 and Figure 1.

Figure 1 shows that the equation of the straight line is

$$
\ln \left(\frac{r}{T}\right)=-\frac{2092}{T}-0.542
$$

Therefore $\left(\Delta \mathrm{H}^{\mathrm{o}} / \mathrm{R}\right)$ is equal to $2092 \mathrm{~K}$ and the $\ln (\mathrm{M})$ is equal to 0.542 and $\Delta S=196.68 \mathrm{~J} / \mathrm{mol}$. The value of $\Delta \mathrm{H}^{\mathrm{o}} / \mathrm{R}$ can be used in (11) to calculate the rate of reaction at different temperature $\left(30,35,40,45\right.$, and $\left.50^{\circ} \mathrm{C}\right)$ and at different concentration $(0.1,0.2,0.3,0.4$, and $0.5 \mathrm{M})$ by using Rung-Kutta method as shown in Table 3.

Gibbs free energy at temperature $298 \mathrm{~K}$ was calculated by the following Gibbs free energy equation [24]:

$$
\begin{aligned}
\Delta G & =\Delta H-T . \Delta S \\
\Delta G^{\mathrm{o}} & =17392.89 \mathrm{~J} / \mathrm{mol}-298 \mathrm{~K} \times 196.679 \mathrm{~J} / \mathrm{mol} . \mathrm{K} \\
& =-41217.32 \mathrm{~J} / \mathrm{mol}
\end{aligned}
$$

The minus sign in Gibbs free energy indicates that the reaction of mild steel with sulfuric acid was a spontaneous reaction [24].

To calculate the order of reaction (n) for mild steel in sulfuric acid $\ln (\mathrm{r})$ versus $\ln (\mathrm{C})$ was plotted according to the following equation [24]:

$$
\mathrm{r}=\frac{d c}{d t}=K C^{\mathrm{n}}
$$

where $(r)$ is the rate of reaction, $(K)$ is the rate of reaction constant, and (n) is the order of reaction. Take the ln function for both sides of (15) to get

$$
\ln (r)=n \ln (C)+\ln (K)
$$

If $\ln (r)$ versus $\ln (C)$ is plotted according to (16), a straight line is obtained. The slope of straight line represents the order of reaction $(\mathrm{n})$ and the intercept is the rate of reaction constant $\ln (\mathrm{K})$ as shown in Table 3 and Figure 2. 
TABLE 3: The rate of reaction $\left(\mathrm{mg} / \mathrm{cm}^{2} . \mathrm{h}\right)$ of mild steel in sulfuric acid at different concentration $(0.1-0.5 \mathrm{M})$ and at different temperature $\left(30-50^{\circ} \mathrm{C}\right)$.

\begin{tabular}{lccccc}
\hline $\begin{array}{l}\text { Concentration } \\
\mathrm{H}_{2} \mathrm{SO}_{4}(\mathrm{M})\end{array}$ & $30^{\circ} \mathrm{C}^{*}$ & $35^{\circ} \mathrm{C}$ & \multicolumn{2}{c}{ Rate of reaction $\left(\mathrm{mg} / \mathrm{cm}^{2} \cdot \mathrm{h}\right)$ at } & $45^{\circ} \mathrm{C}$ \\
\hline 0.1 & 0.175 & 0.198961 & 0.225336 & 0.25427462 & 0.285929 \\
0.2 & 22.48125 & 25.55936 & 28.94761 & 32.6652073 & 36.73163 \\
0.3 & 44.7875 & 50.91976 & 57.66988 & 65.0761399 & 73.17734 \\
0.4 & 67.09375 & 76.28016 & 86.39215 & 97.4870725 & 109.623 \\
0.5 & 89.94 & 102.2545 & 115.8097 & 130.682624 & 146.951 \\
\hline
\end{tabular}

* denotes experimental data and other data are theoretical data that were found by Runge-Kutta method.

TABLE 4: The rate of reaction constant of mild steel in sulfuric acid at different temperature $\left(30-50^{\circ} \mathrm{C}\right)$.

\begin{tabular}{lcc}
\hline Temperature $\left({ }^{\circ} \mathrm{C}\right)$ & $1 / \mathrm{T}(\mathrm{K})$ & \multicolumn{2}{c}{ Rate of reaction constant } \\
\hline 30 & & $\mathrm{~K}$ \\
35 & 0.0032987 & 2617.56559 \\
40 & 0.00324517 & 2659.78348 \\
45 & 0.00319336 & 2705.38633 \\
50 & 0.00314317 & 2749.02065 \\
\hline
\end{tabular}

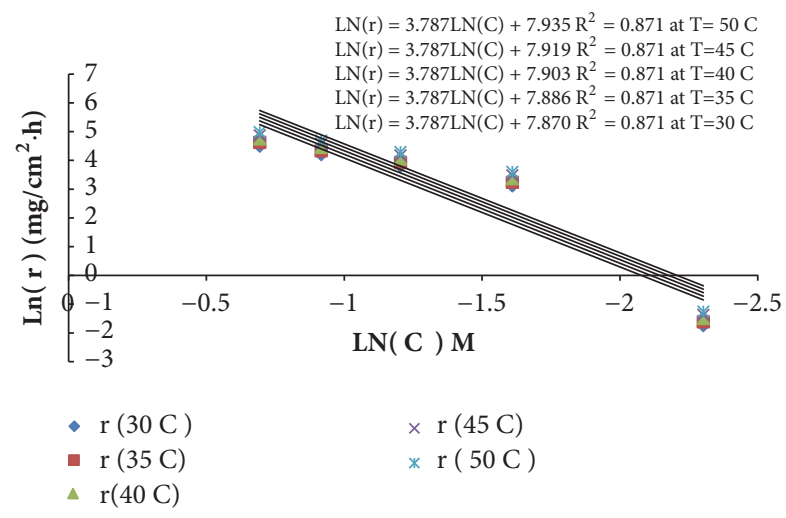

FIGURE 2: $\ln (\mathrm{r})$ versus $\ln (\mathrm{C})$ of mild steel in sulfuric acid at different concentration $(0.1-0.5 \mathrm{M})$ and at different temperature $\left(30-50^{\circ} \mathrm{C}\right)$.

The rate of reaction equations at different temperatures $\left(30-50^{\circ} \mathrm{C}\right)$ was found as shown in Figure 2:

$$
\begin{array}{ll}
\ln (r)=3.787 \ln (C)+7.935 & \text { at } T=50 C \\
\ln (r)=3.787 \ln (C)+7.919 & \text { at } T=45 C \\
\ln (r)=3.787 \ln (C)+7.903 & \text { at } T=40 C \\
\ln (r)=3.787 \ln (C)+7.886 & \text { at } T=35 C \\
\ln (r)=3.787 \ln (C)+7.870 & \text { at } T=30 C
\end{array}
$$

The order of reaction of sulfuric acid with mild steel is a $4^{\text {th }}$-order reaction as shown in (17), (18), (19), (20), and (21) at the range of temperature $\left(30-50^{\circ} \mathrm{C}\right)$. The rate of reaction constant increases with an increase in temperature because the kinetic energy of molecules increases with increase in

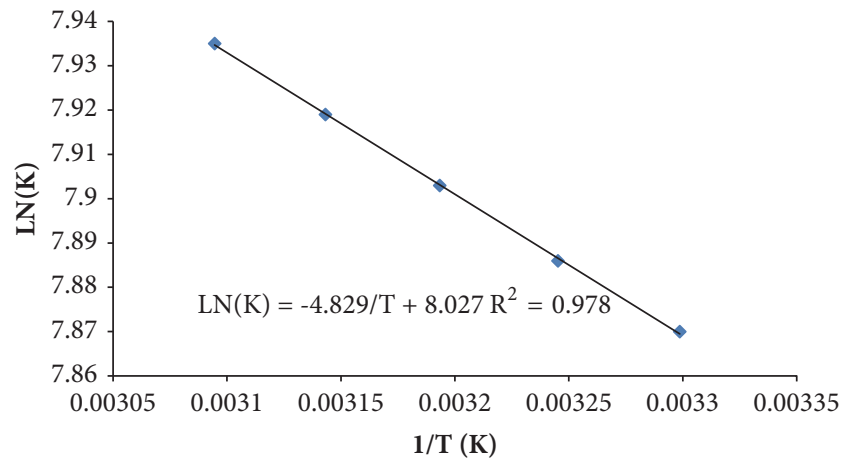

Figure $3: \ln (\mathrm{K})$ versus $(1 / \mathrm{T})$ of mild steel in sulfuric acid at different temperature $\left(30-50^{\circ} \mathrm{C}\right)$.

temperature $[24,25]$ as shown in Table 4 and Figure 3. To find the activation energy $(\mathrm{E}), \ln (\mathrm{K})$ versus $(1 / \mathrm{T})$ was plotted according to the following equations [24] below and the results are shown in Figure 3 and Table 3:

$$
\begin{gathered}
K=A e^{-E / R T} \\
\ln (K)=-\frac{E}{R T}+\ln (A)
\end{gathered}
$$

The plot of $\ln (\mathrm{K})$ versus (1/T) according to (23) obtains a straight line, the slope of which represents the activation energy of a reaction $(\mathrm{E} / \mathrm{R})$ and the intercept is equal to the preexponential factor $(\mathrm{A})$.

The activation energy (E/R) for the reaction of mild steel with sulfuric acid was estimated from the slope as shown in Table 3 and Figure 3 and was found equal to $4.829 \mathrm{~K}$ for the 
temperature range of $30-50^{\circ} \mathrm{C}$ and the preexponential factor (A) was 3062.54 as shown in the following equation:

$$
\ln (K)=-\frac{4.829}{T}+8.027
$$

The value of activation energy was very low, indicating that mean of the reaction takes place easily and spontaneously, which is in agreement with the result of minus value of Gibbs free energy.

\section{Conclusion}

The corrosion kinetics of mild steel with sulfuric acid in combination with the experimental data and theoretical approach using the Runge-Kutta method was investigated. The rates of sulfuric acid reaction with mild steel were increased with increased temperatures. Moreover, the rates of reaction constant $(\mathrm{K})$ at temperature range of $30-50^{\circ} \mathrm{C}$ were $2618-2793 \mathrm{~L}^{3} / \mathrm{mol}^{3} . \mathrm{h}$, respectively. The reaction order of mild steel was $4^{\text {th }}$ order in all ranges of temperature $\left(30-50^{\circ} \mathrm{C}\right)$. The enthalpy and entropy of reaction were 17.393 $\mathrm{KJ} / \mathrm{mol}$ and $196.68 \mathrm{~J} / \mathrm{mol}$, respectively. The value of Gibbs free energy was minus value $(-41.217 \mathrm{KJ} / \mathrm{mol})$, and therefore it was concluded that the reaction of mild steel with sulfuric acid was spontaneous. The activation energy of the reaction of mild steel with sulfuric acid was calculated and it was very low $(\mathrm{E} / \mathrm{R}=4.829 \mathrm{~K})$ at different temperatures and at different concentration of sulfuric acid, which leads to concluding that the reaction of a mild steel with sulfuric acid readily occurred. Runge-Kutta simulation technique can be used to simulate the corrosion of mild steel surface in different concentrations of $\mathrm{H}_{2} \mathrm{SO}_{4}$.

\section{Data Availability}

The data used to support the findings of this study are available from the corresponding author upon request.

\section{Conflicts of Interest}

The author declares that he has no conflicts of interest.

\section{References}

[1] M. A. Migahed, A. M. Abdul-Raheim, A. M. Atta, and W. Brostow, "Synthesis and evaluation of a new water soluble corrosion inhibitor from recycled poly(ethylene terphethalate)," Materials Chemistry and Physics, vol. 121, no. 1-2, pp. 208-214, 2010.

[2] D. D. N. Singh, T. B. Singh, and B. Gaur, "The role of metal cations in improving the inhibitive performance of hexamine on the corrosion of steel in hydrochloric acid solution," Corrosion Science, vol. 37, no. 6, pp. 1005-1019, 1995.

[3] G. E. Badr, "The role of some thiosemicarbazide derivatives as corrosion inhibitors for C-steel in acidic media," Corrosion Science, vol. 51, no. 11, pp. 2529-2536, 2009.

[4] D. Asefi, M. Arami, and N. M. Mahmoodi, "Electrochemical effect of cationic gemini surfactant and halide salts on corrosion inhibition of low carbon steel in acid medium," Corrosion Science, vol. 52, no. 3, pp. 794-800, 2010.

[5] K. Zhang, B. Xu, W. Yang, X. Yin, Y. Liu, and Y. Chen, "Halogensubstituted imidazoline derivatives as corrosion inhibitors for mild steel in hydrochloric acid solution," Corrosion Science, vol. 90, pp. 284-295, 2015.

[6] R. Yıldız, "An electrochemical and theoretical evaluation of 4,6diamino-2-pyrimidinethiol as a corrosion inhibitor for mild steel in $\mathrm{HCl}$ solutions," Corrosion Science, vol. 90, pp. 544-553, 2015.

[7] N. A. Odewunmi, S. A. Umoren, and Z. M. Gasem, "Watermelon waste products as green corrosion inhibitors for mild steel in $\mathrm{HCl}$ solution," Journal of Environmental Chemical Engineering, vol. 3, no. 1, pp. 286-296, 2015.

[8] G.-F. Sui, J.-S. Li, H.-W. Li, F. Sun, T.-B. Zhang, and H.$\mathrm{Z}$. Fu, "Investigation on the explosive welding mechanism of corrosion-resisting aluminum and stainless steel tubes through finite element simulation and experiments," International Journal of Minerals, Metallurgy, and Materials, vol. 19, no. 2, pp. 151158, 2012.

[9] J.-J. Shi and W. Sun, "Electrochemical and analytical characterization of three corrosion inhibitors of steel in simulated concrete pore solutions," International Journal of Minerals, Metallurgy, and Materials, vol. 19, no. 1, pp. 38-47, 2012.

[10] K.-K. Wang, "Thixo-forging and simulation of complex parts of aluminum alloy AlSi7Mg," International Journal of Minerals, Metallurgy, and Materials, vol. 17, no. 1, pp. 53-57, 2010.

[11] S.-H. Yin, A.-X. Wu, S.-Y. Wang, and H.-J. Wang, "Simulation of solute transportation within porous particles during the bioleaching process," International Journal of Minerals, Metallurgy, and Materials, vol. 17, no. 4, pp. 389-396, 2010.

[12] X.-C. Liu, L.-F. Cheng, L.-T. Zhang, X.-G. Luan, and H. Mei, "Behavior of pure and modified carbon/carbon composites in atomic oxygen environment," International Journal of Minerals, Metallurgy, and Materials, vol. 21, no. 2, pp. 190-195, 2014.

[13] S.-W. Yin, L. Wang, L.-G. Tong, F.-M. Yang, and Y.-H. Li, "Kinetic study on the direct nitridation of silicon powders diluted with $\alpha-\mathrm{Si}_{3} \mathrm{~N}_{4}$ at normal pressure," International Journal of Minerals, Metallurgy, and Materials, vol. 20, no. 5, pp. 493498, 2013.

[14] K. F. Khaled and A. El-Maghraby, "Experimental, Monte Carlo and molecular dynamics simulations to investigate corrosion inhibition of mild steel in hydrochloric acid solutions," Arabian Journal of Chemistry, vol. 7, no. 3, pp. 319-326, 2014.

[15] S. K. Saha, P. Ghosh, A. Hens, N. C. Murmu, and P. Banerjee, "Density functional theory and molecular dynamics simulation study on corrosion inhibition performance of mild steel by mercapto-quinoline Schiff base corrosion inhibitor," Physica E: Low-dimensional Systems and Nanostructures, vol. 66, pp. 332341, 2015.

[16] G. S. Fontes, P. F. F. e Melo, and A. S. D. M. Alves, Nuclear Engineering and Design, vol. 293, p. 485, 2015.

[17] D. Lu, Y. Liu, and X. Zeng, "Experimental and numerical study of dynamic response of elevated water tank of AP1000 PCCWST considering FSI effect," Annals of Nuclear Energy, vol. 81, pp. 7383, 2015.

[18] L. Li, J. Zhang, W. Song, Y. Fu, X. Xu, and Y. Chen, "CATE: a code for activated corrosion products evaluation of watercooled fusion reactor," Fusion Engineering and Design, vol. 100, pp. 340-344, 2015.

[19] F. Clarelli, B. De Filippo, and R. Natalini, "Mathematical model of copper corrosion," Applied Mathematical Modelling: 
Simulation and Computation for Engineering and Environmental Systems, vol. 38, no. 19-20, pp. 4804-4816, 2014.

[20] S. T. Karris, Numerical Analysis Using MATLAB and Spreadsheets, Orchard Publications, 2nd edition, 2004.

[21] V. G. Jenson and G. V. Jeffreys, Mathematical Methods in Chemical Engineering, Academic press, London, UK, 2nd edition, 1981.

[22] A. Ostovari, S. M. Hoseinieh, M. Peikari, S. R. Shadizadeh, S. J. Hashemi, and Sci. Corros, "Corrosion inhibition of mild steel in $1 \mathrm{M} \mathrm{HCl}$ solution by henna extract: a comparative study of the inhibition by henna and its constituents (Lawsone, Gallic acid, $\alpha$-d-Glucose and Tannic acid)," Corrosion Science, vol. 51, no. 9, pp. 1935-1949, 2009.

[23] A. K. Singh and M. A. Quraishi, "Effect of Cefazolin on the corrosion of mild steel in $\mathrm{HCl}$ solution," Corrosion Science, vol. 52, no. 1, pp. 152-160, 2010.

[24] J. M. Simth, Chemical Engineering Kinetics, Singapore, McGrawHill, 3rd edition, 1981.

[25] A. A. Taker, Physical Chemistry For Polymer, Mosal University Editions, Mosul, Iraq, 1984. 


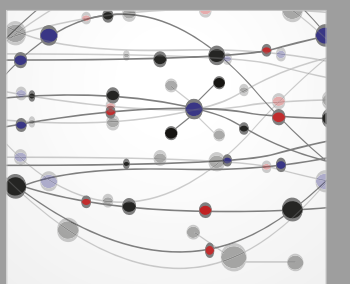

The Scientific World Journal
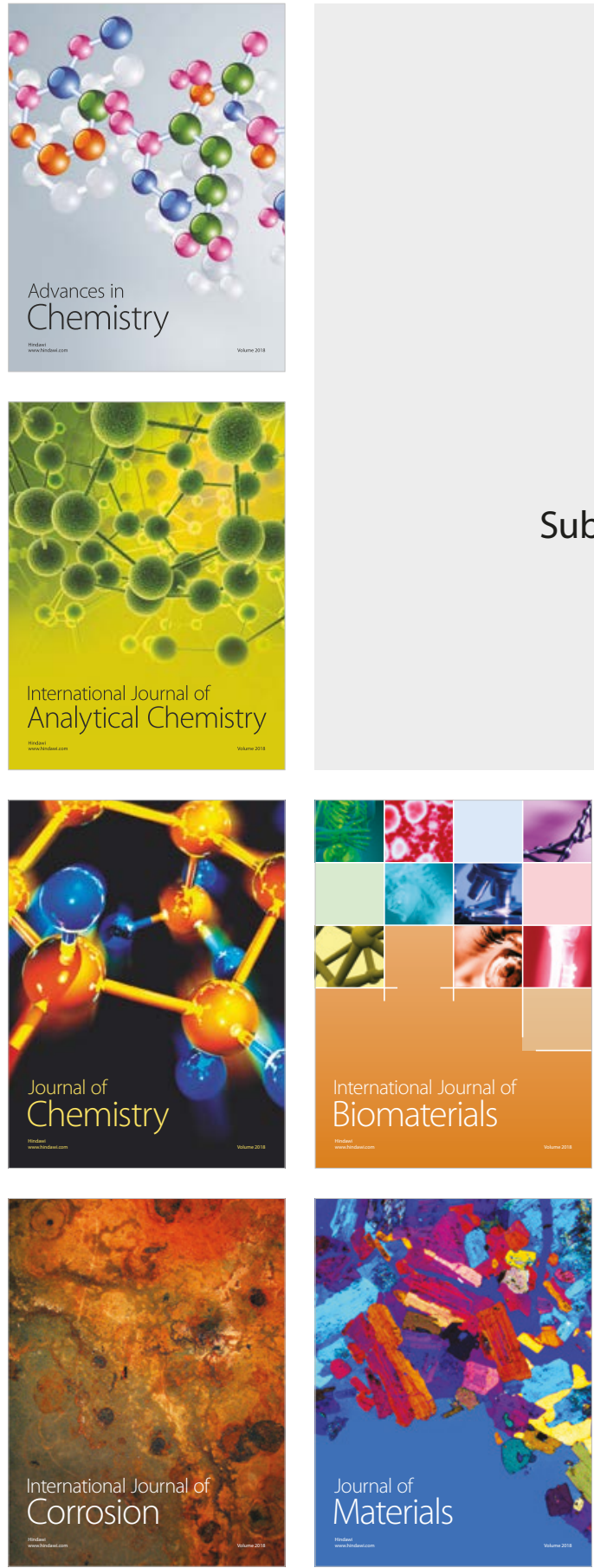

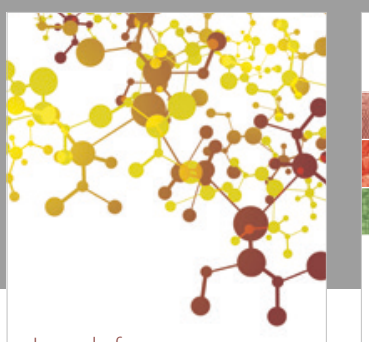

Journal of

Applied Chemistry
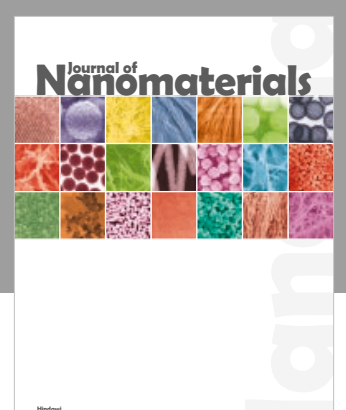

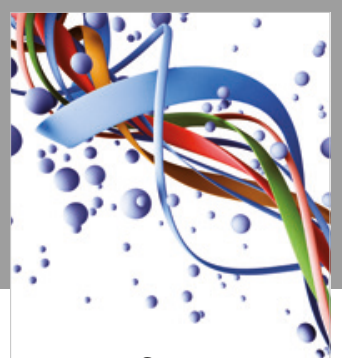

Scientifica

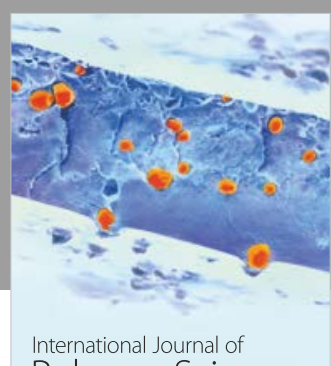

Polymer Science

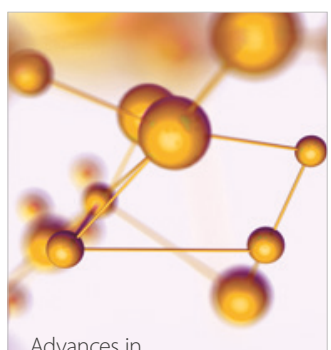

Physical Chemistry
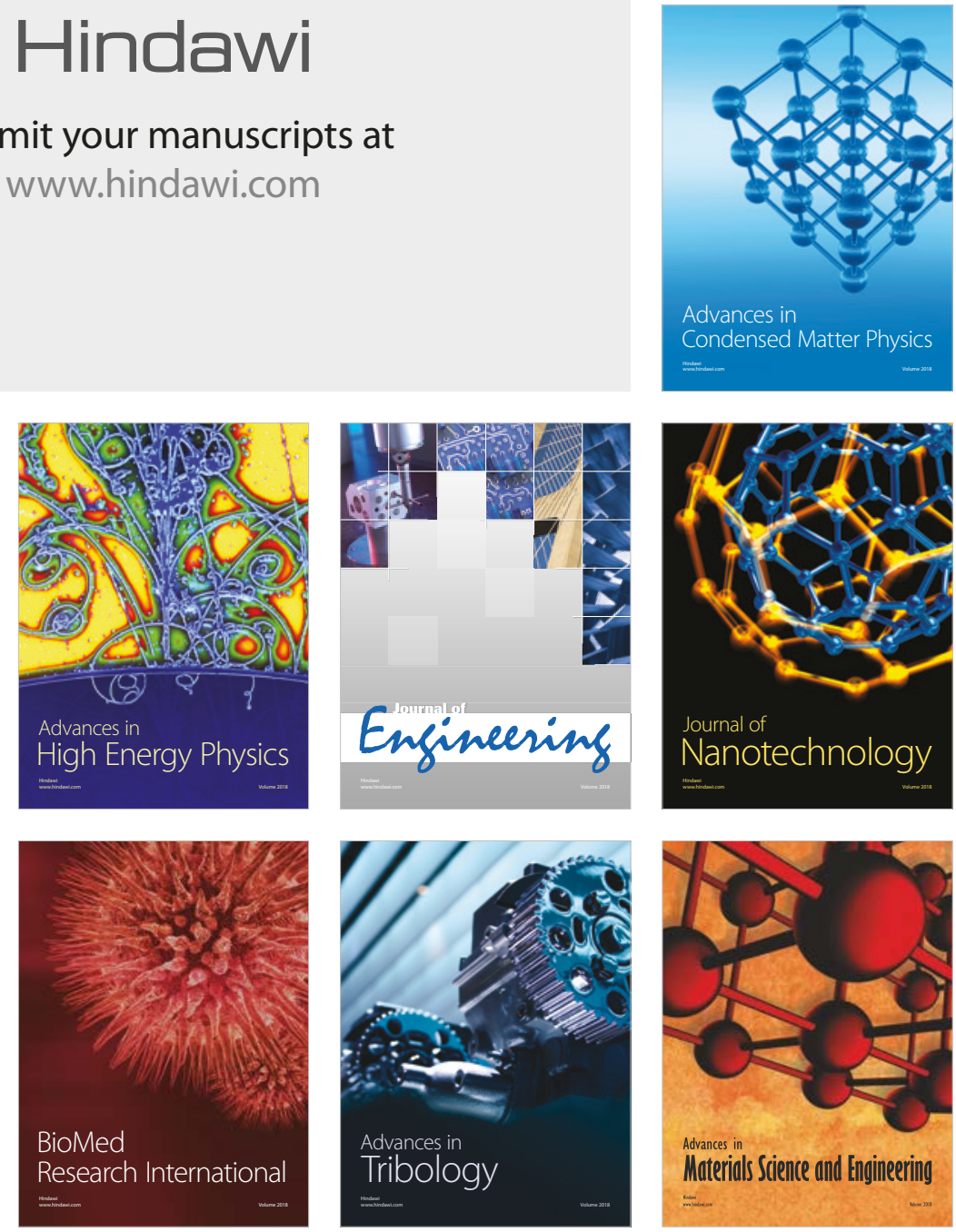